\title{
POLÊMICAS DO TRIBUNAL DE CONTAS DO PARANÁ EM 2015
}

\author{
Fernando Marcelino Pereira ${ }^{1}$
}

- Enviado em 16/03/2016

- Aprovado em 24/04/2016

O objetivo deste texto é abordar brevemente algumas notícias polêmicas sobre a ação do Tribunal de Contas do Paraná em 2015.

Em fevereiro de 2015 o Tribunal de Contas do Estado do Paraná (TCE-PR) decidiu conceder auxílio-moradia para conselheiros, auditores e procuradores. Vinte pessoas beneficiadas com um acréscimo de $\mathrm{R} \$ 4.377,74$ no salário. Tem direito ao benefício mesmo quem já possui um imóvel. Não será preciso prestar informações sobre a destinação deste recurso extra. Na prática, o auxílio-moradia é uma espécie de "aumento extraoficial" de salário ${ }^{2}$. O custo anual aos cofres públicos será de cerca de $\mathrm{R} \$ 1$ milhão ${ }^{3}$.

Em março de 2015, dois conselheiros ganharam indenizações por férias atrasadas:

Depois de autoconceder auxílio-moradia no valor de $\mathrm{R} \$ 4.377,74$ para seus conselheiros, auditores e procuradores, o Tribunal de Contas do Estado (TC) se envolveu em nova polêmica financeira. Por decisão do Pleno do órgão, pelo menos dois conselheiros, Nestor Baptista e Artagão de Mattos Leão, tiveram o direito de receber férias não gozadas ou interrompidas desde a década de 1990. No caso de Baptista, o benefício equivale a 288 dias, entre 1992 e 2012. Já Artagão tem direito ao pagamento de 361 dias, de 2002 a 2013. Ambos os casos tiveram como relator o conselheiro Fernando Guimarães e foram

\footnotetext{
${ }^{1}$ Graduado em Relações Internacionais pela UNICURITIBA, Mestre em Ciência Política e Doutorando em Sociologia pela UFPR. Membro do Núcleo de Estudos Paranaenses (NEP). Endereço eletrônico: fernandomarcelinopereira@gmail.com
}

2 Disponível em http://www.gazetadopovo.com.br/vida-publica/tc-aprova-auxilio-moradia-de-r-43-milek2m0grmhw83475hi19aapwlq. Acesso 29.fev.2016.

\footnotetext{
${ }^{3}$ A principal justificativa apresentada pelos conselheiros do TCE-PR para a aprovação do auxílio-moradia foi a equiparação de direito com outros tribunais de contas brasileiros, além de órgãos como o Tribunal de Justiça do Paraná (TJ-PR) e Ministério Público do Paraná (MP-PR). Atualmente, os cerca de 800 juízes e desembargadores do TJ-PR recebem R \$ 4,4 mil por mês de auxílio moradia. $\mathrm{O}$ benefício também é pago mesmo para aqueles que já possuem residência na cidade onde trabalham, e não é preciso comprovar os gastos com residência ao tribunal.
} 
aprovados por unanimidade [...]. Como atualmente o salário bruto dos conselheiros é de R\$ 26.589,68, a indenização de Baptista gira em torno de $\mathrm{R} \$ 340$ mil. Artagão, por sua vez, recebeu aproximadamente $\mathrm{R} \$ 425$ mil. O pagamento, porém, não ficará restrito aos dois conselheiros ${ }^{4}$.

Em junho de 2015 uma nova polêmica envolveu o ex-deputado estadual Cleiton Kielse, filho do ex-conselheiro do Tribunal Quiélse Crisóstomo da Silva, falecido em 2006. Kielse queria aumentar em $80 \%$ o salário de técnico de controle no TCE-PR, com efeitos retroativos desde 2004. Kielse foi empossado no TC em 1994 em cargo de nível médio, quando já exercia mandato na Assembleia. Na época, seu pai era conselheiro do TC. No dia seguinte à posse, ele pediu licença do cargo no tribunal para exercer o mandato eletivo. Os pedidos de licença foram sendo renovados até fevereiro de 2015, pois nas eleições de 2014 ele não conseguiu se eleger para um sétimo mandato. Após 20 anos afastado, ele retornou ao Tribunal em fevereiro de 2015. Dezenove dias depois, solicitou outra licença à qual tinha direito por tempo de serviço e ficou afastado do TC por mais cinco meses. Assim que retornou, o ex-deputado pediu que fosse reenquadrado retroativamente desde 2004 como funcionário de nível superior, uma vez que ele se formou em Direito pela Universidade Tuiuti em 1998. Isso resultaria em um aumento de $80 \%$ do seu salário bruto - hoje, é de R \$ 6,1 mil. Se o aumento for aprovado, passaria a R\$12,4 mil. Além do salário, Kielse recebe um adicional por tempo de serviço de $\mathrm{R} \$ 1,2$ mil, mesmo só tendo trabalhado no TC por alguns meses. O pedido de reenquadramento do ex-deputado estadual Cleiton Kielse (PMDB) foi arquivado pelo TCE-PR 5 .

Em outubro de 2015 a Gazeta do Povo publicou matéria chamada "Dos 7 conselheiros do Tribunal de Contas do Paraná, 2 estão sub judice e 3 são suspeitos de ilegalidades". De acordo com a matéria, dos sete conselheiros que integram o Tribunal de Contas do Paraná, pelo menos cinco enfrentam situações polêmicas:

Artagão de Mattos Leão, Fernando Guimarães e Durval Amaral são suspeitos de participar de esquemas de corrupção. Já Fabio Camargo e Ivan Bonilha têm seu cargo sub júdice devido a questionamentos relacionados à eleição. Artagão de Mattos Leão foi investigado pelo Gaeco por suposta fraude em licitação para construção de um prédio anexo do TC,

\footnotetext{
4 Disponível em http://www.gazetadopovo.com.br/vida-publica/conselheiros-do-tc-ganham-indenizacao-por-ferias-
} atrasadas-37g9rd4polqvb4hqzwc3i28sv. Acesso em 29.fev.2016.

${ }^{5}$ Disponível http://www.gazetadopovo.com.br/vida-publica/apos-atuar-19-dias-no-tc-em-21-anos-kielse-quer-reajustedjy2gwl0mgi43fhbewnl6r1wq. Acesso 29.fev.2016. 
realizada durante seu mandato como presidente, no valor de $\mathrm{R} \$ 36,4$ milhões. Seis pessoas foram denunciadas - incluindo três servidores ligados à sua gestão. Artagão é alvo de sindicância no Superior Tribunal de Justiça (STJ), que corre sob sigilo. Fernando Guimarães foi acusado de receber dinheiro do Instituto Confiancce, Organização Social Civil de Interesse Público (Oscip) que atua na área de saúde e é acusada de desviar dinheiro do SUS e de prefeituras - que devem ser fiscalizadas pelo próprio TC. Em oito anos, a Oscip recebeu R\$ 355 milhões de municípios paranaenses. A esposa de Guimarães, Kelli Cristina Galli Guimarães, é sobrinha da diretora do instituto, Cláudia Galli, e trabalhou no Confiancce por 12 anos. O caso de Durval Amaral veio à tona recentemente, mas é anterior a sua eleição para o TC. Ele é acusado pelo doleiro Alberto Youssef de receber R\$ 2 milhões do esquema Copel/Olvepar. O caso é de 2002, época em que Amaral era deputado estadual e líder do governo Lerner na Assembleia. O conselheiro aposentado do TC Heinz Herwig também foi acusado de participar do esquema. Amaral também foi citado na delação de Luiz Antônio de Souza referente à Operação Publicano - assim como seu filho, o deputado estadual Tiago Amaral (PSB). Entretanto, não se sabe o teor da delação. Já Fabio Camargo e o atual presidente do TC, Ivan Bonilha, enfrentam problemas por causa das eleições para o cargo de conselheiro. Conforme a ação de um candidato derrotado na disputa para o cargo, Max Schrappe, Camargo não apresentou a documentação exigida, tampouco fez o mínimo de votos para ser eleito - 27 de 54, exatamente metade. Camargo chegou a ficar afastado do TC por mais de um ano, por decisão do Supremo Tribunal Federal (STF). Em setembro, ele foi reconduzido ao cargo, mas o mérito da ação ainda está pendente de julgamento. Já o caso de Bonilha não envolve questionamentos envolvendo sua eleição, mas sim a de seu antecessor, Maurício Requião. Eleito em 2008, o irmão do ex-governador Roberto Requião (PMDB) foi afastado do cargo pelo ministro do Supremo Tribunal Federal (STF) Ricardo Lewandowski, que viu irregularidades na sua eleição - entre elas, ter sido iniciada antes da aposentadoria do seu antecessor e a relação de parentesco do ex-conselheiro com o então governador. Sua eleição foi anulada e a Assembleia elegeu Bonilha para a mesma vaga. Ele recorre da decisão. Em 19 de outubro de 2015, o Órgão Especial do Tribunal de Justiça (TJ) decidiu, por 9 votos a 8, que Maurício não tem direito à cadeira. Mas ele deve recorrer novamente da decisão. Caso consiga voltar ao TC, passaria a ocupar a vaga de Bonilha ${ }^{6}$.

Em novembro o TCE-PR decidiu manter o conselheiro Durval Amaral na relatoria das contas do governo do Paraná de 2014. O Ministério Público de Contas havia contestado a indicação do relator, alegando a proximidade entre Durval Amaral e o governador Beto Richa, que poderia comprometer sua atuação. Todos os seis conselheiros que votaram na sessão optaram por sua permanência. Para o Ministério Público de Contas, a posição de Durval previa assistência direta e imediata ao governador e criava uma estreita relação de confiança entre os dois. Entre 2011 e 2012, Amaral ocupou o cargo de Secretário da Casa Civil no primeiro mandato de Beto Richa como governador. Os promotores do Ministério Público de Contas argumentaram que, apesar das contas serem referentes a um período em que Amaral não ocupava mais o cargo de secretário-chefe da Casa Civil, não se pode acreditar que a relação de confiança tenha se esvaído. Conforme trecho do documento, "parecenos indene de dúvidas que, almejando desde o início da gestão o pleno sucesso do mandato do

\footnotetext{
${ }^{6}$ Disponível em http://www.gazetadopovo.com.br/vida-publica/dos-7-conselheiros-do-tribunal-de-contas-do-parana-2estao-sub-judice-e-3-sao-suspeitos-de-ilegalidades-emgefw5wxn3xga64da7kgk2jk
} 
Governador (e não se pode esperar outra coisa do Chefe da Casa Civil), esse fato por si só influencia a condução processual correspondente"7.

A relação entre os dois é tão boa que, em 2009, quando ainda era prefeito de Curitiba, Beto Richa chegou a dizer, segundo registrou um jornal de Cambé, que Durval é um "amigo" e "irmão"8. Ambos fizeram campanhas juntos em 2010, quando Richa era candidato ao governo e Durval a deputado estadual. Em vídeo de campanha de Durval para deputado em 2010, Richa diz seguinte:

"Eu falo do Durval de peito aberto, porque eu sempre caminhei ao seu lado”

"Um homem de compromisso, um homem que não abre mão de seus companheiros, que só construiu amizades e respeito."

"Eleito do governador eu mais do que todo mundo vou precisar do Durval Amaral para garantir a governabilidade na Assembleia”

Já Durval agradece dizendo o seguinte:

"Muito obrigado aos novos companheiros que vão levar o Beto Richa para que ele seja o nosso governador do Paraná em cada uma das suas cidades"”.

Ao vencer a eleição, Richa nomeou Durval como seu secretário da Casa Civil - o posto mais importante do governo do estado. Depois toda a base de Richa votou em Durval Amaral para conselheiro do TCE-PR. Depois da eleição de Durval, Richa passou a fazer campanha ao lado do filho do ex-deputado, Tiago Amaral, eleito deputado estadual em 2014. O novo deputado também está na base de Richa na Assembleia. Apesar destes indícios, o Pleno do TCE-PR rejeitou a solicitação para substituir Durval Amaral como relator das contas do governador Beto Richa.

\footnotetext{
7 Disponível em http://g1.globo.com/pr/parana/noticia/2015/11/tce-pr-mantem-durval-amaral-na-relatoria-das-contasestaduais-de-2014.html. Acesso 29.fev.2016.
}

\footnotetext{
${ }^{8}$ Disponível em http://www.jornalnossacidade.com.br/news/index.php?noticia=431. Acesso 29.fev.2016.
}

${ }^{9}$ Disponível em https://www.youtube.com/watch?time_continue=351\&v=Z2rKQKwVXQ4. Acesso 29.fev.2016. 